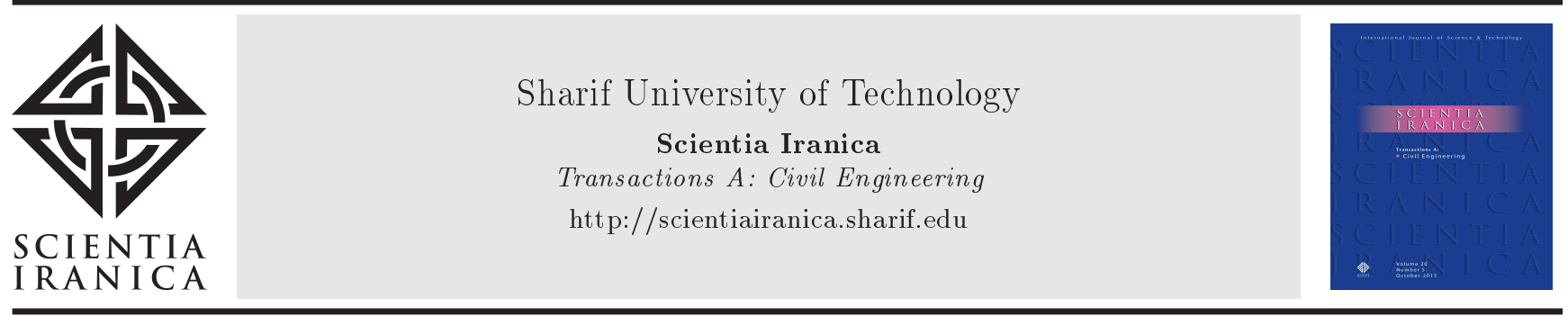

\title{
Effect of distribution patterns of DSM columns on the efficiency of liquefaction mitigation
}

\author{
H. Dehghan Khalili, A. Ghalandarzadeh*, M. Moradi, and R. Karimzadeh \\ School of Civil Engineering, College of Engineering, University of Tehran, Tehran, Iran.
}

Received 6 August 2017; received in revised form 21 May 2018; accepted 19 January 2019

\section{KEYWORDS}

Liquefaction

mitigation;

Deep soil mixing;

Shaking table;

Shear reinforcement.

\begin{abstract}
Liquefaction during earthquakes can result in severe damage to structures, primarily from excess pore water pressure generation and subsoil softening. Deep Soil Mixing (DSM) is a common method of soil improvement and is also used to reduce shear stress in liquefiable soils to control liquefaction. The current study evaluated the effect of DSM columns and the implementation of different column patterns on controlling liquefaction and decreasing settlement of shallow foundations. A series of shaking table physical modeling tests were conducted for three different distribution patterns of DSM columns (i.e., square, triangular, and single) with a treatment area ratio of $30 \%$. The treatment was applied to a liquefiable soil under a shallow model foundation. The results showed that the excess pore water pressure decreased by $20 \%$ to $50 \%$ in comparison with the unimproved soil, depending on the DSM column pattern used. For improved soil, the shallow foundation settlement was about $10 \%$ more than that of the unimproved soil in the best case. Increase in soil shear stiffness after the use of the DSM columns was compared with the results of existing practical relations to increase soil shear strength.
\end{abstract}

(C) 2020 Sharif University of Technology. All rights reserved.

\section{Introduction}

Liquefaction is a destructive phenomenon that occurs in loose, saturated, sandy soils during an earthquake. It was the cause of heavy damage in the Niigata (1964) [1], Alaska (1964) [2], and Kobe (1995) [3] earthquakes. In all of these cases, liquefaction-induced deformation (e.g., lateral spreading) caused slope failure, failure of the foundations of bridges and buildings, and the destruction of underground structures. When rapid two-way shear stress is imposed on saturated sandy soil by seismic movement, it triggers an increase in Pore Water Pressure (PWP) [4]. The PWP increases rapidly in loose cohesionless saturated soil and may

*. Corresponding author. Tel.: +98 2166462616 ;

Fax: +982166403808

E-mail address: aghland@ut.ac.ir (A. Ghalandarzadeh) result in the suspension of soil grains and soil strength and stiffness falling to zero for a few moments [5]. The behavior of the sand suddenly changes from solid to liquid and could behave like a viscous flow. It is challenging to compare the different methods of controlling liquefaction in susceptible soil to choose the most appropriate method. The installation of vertical discrete columns (stone, Deep Soil Mixing (DSM), or jet grouting columns) is a popular method to deal with loose, saturated, cohesionless soils. The elements are set in a wall or single pattern to enclose the soil mass. The shear strain caused by an earthquake reduces as the average shear stiffness of the soil mass increases, leading to a decrease in the excess pore pressure. This provides a barrier to the transmission of excess PWP from an unimproved area to the improved area [5]. Even if liquefaction occurs, lateral soil deformation or vertical settlement of the foundations will decrease because of the inherent resistance of the columns.

A limited number of case studies have been 
used to evaluate the performance of DSM columns; however, during the Kobe earthquake (1995), it was observed that DSM walls performed effectively $[6,7]$. The efficiency and performance of single-axis DSM or wall pattern columns in preventing liquefaction were analytically investigated and numerically simulated. The investigations showed that the treatment area ratio was a major parameter for controlling DSM grid effectiveness [6,8-10].

Numerical simulations [11-13] suggest that DSM columns deform under shear stress and in flexure such that the benefit of shear reinforcement mechanisms decreases significantly. DSM grid performance has also been studied using physical modeling. The results of centrifuge tests $[10,11]$ demonstrate that wall spacing, wall depth, and input motion frequency are effective variables in shear grid performance to reduce excess PWP generated in saturated, loose sands.

The shear reinforcement mechanism of DSM columns is often studied by assuming that the columns and surrounding soil exhibit shear strain deformation compatibility. Based on this assumption, a significant portion of earthquake-induced shear stress is absorbed by the stiffer elements of the system (DSM columns) and causes a considerable decrease in the cyclic stress ratio in the surrounding soil and the potential of liquefaction [14,15].

The estimated increase of soil shear strength induced by DSM columns can be determined by different methods. One method is the relation provided for and extended to soil-cement columns that assumes shear strain compatibility between columns and the surrounding soil $[14,15]$. The second is theoretical bounds [16]. The third is the design equation which considers differences in the shear strain between columns and the surrounding soil. These analytical methods can be used to evaluate the average shear modulus for improved and unimproved soils. The finite element analysis developed by this method showed that shear strain incompatibility increased as the stiffness of discrete columns increased [17]. For a realistic area replacement ratio for DSM columns, only a $10 \%$ to $30 \%$ decrease in shear stress is achievable [18].

The potential decrease in liquefaction and shear stress using DSM columns in the soil has not been investigated quantitatively. The effects of different design variables (column implementation pattern, column length, and treatment area ratio) have not been thoroughly explored. In the current study, a series of shaking table physical modeling tests were conducted to evaluate the quantitative effect of DSM columns and the effectiveness of the implementation of different column patterns to control liquefaction and shallow foundation settlement. The relationship presented by Rayamajhi et al. (2013) [17] was investigated to estimate an increase in shear strength induced by DSM columns. The application of DSM columns to reduce the liquefaction risk and determine the optimal implementation of column patterns was also investigated.

\section{Shaking table tests}

\subsection{Test method}

Table 1 compares the factors related to the model and prototype. The procedure for the simulation of $1 \mathrm{~g}$ shaking table tests was proposed by Iai and Sugano (1999) [19]. Table 1 provides information about scaling factors and selected values in the tests.

Firouzkooh sand $\left(G s=2.69, e_{\max }=0.87\right.$, and $\left.e_{\min }=0.608\right)$ was used to create the model ground, which consists of two layers. The bottom layer was $50 \mathrm{~cm}$ in height, assumed to be non-liquefiable, and compacted to achieve $90 \%$ of the maximum soil density. The upper layer was $45 \mathrm{~cm}$ in height and was made liquefiable using the wet tamping method at a relative density of $20 \%$. The groundwater level was $5 \mathrm{~cm}$ below the soil surface.

The 45-cm soil-cement columns were fabricated with a diameter of $5 \mathrm{~cm}$ inside the liquefiable soil using a DSM apparatus designed and built for this purpose (Figure 1). The soil-cement mixing was done by a shaft having six blades and two nozzles with a rotation speed of $20 \mathrm{rpm}$, a penetration rate of $1 \mathrm{~m} / \mathrm{min}$, and a withdrawal speed of $0.5 \mathrm{~m} / \mathrm{min}$. Figure 2 shows that the DSM columns created by this machine are high-quality and homogeneous with a constant diameter throughout. For each column, $400 \mathrm{cc}$ of the grout was injected into the soil. Ordinary Portland cement grout with a water-cement ratio of 1:6 was used to construct the columns to produce the

Table 1. Comparison of $1 \mathrm{~g}$ test for model and prototype.

\begin{tabular}{cccc}
\hline $\boldsymbol{N}=\mathbf{2 5}$ & Model/Prototype & Prototype & Model \\
\hline Scale & $1 / N$ & 1 & 0.04 \\
DSM diameter & $1 / N$ & $125 \mathrm{~cm}$ & $5 \mathrm{~cm}$ \\
Frequency & $N^{.5}$ & $0.6 \mathrm{~Hz}$ & $3 \mathrm{~Hz}$ \\
Acceleration & 1 & $0.35 \mathrm{~g}$ & $0.35 \mathrm{~g}$ \\
DSM flexural rigidity (EI) & $N^{-4.5}$ & $10^{5}$ & $10^{-4}$ \\
Foundation stress & $1 / N$ & $30 \mathrm{kPa}$ & $1.2 \mathrm{kPa}$ \\
\hline
\end{tabular}



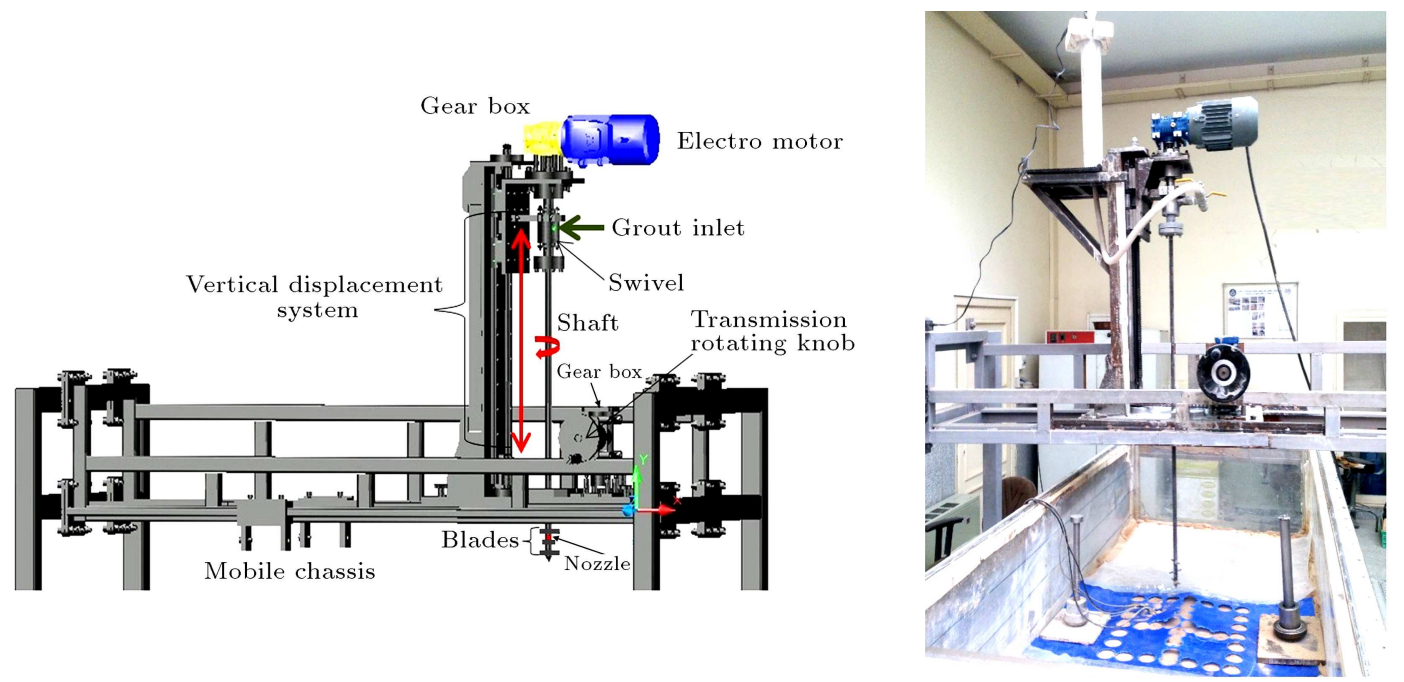

Figure 1. Soil mixing apparatus.

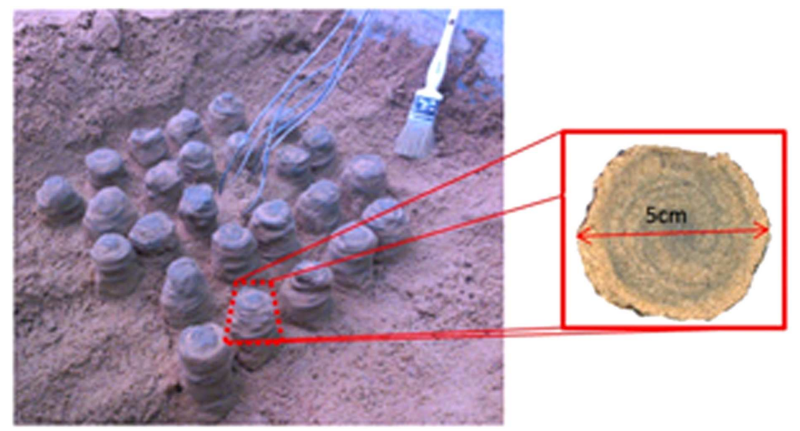

Figure 2. Soil mixing columns $(D=5 \mathrm{~cm}$ and $H=45$ $\mathrm{cm})$.

targeted unconfined compressive strength of $0.35 \mathrm{MPa}$ after three days of curing.

\subsection{Testing program}

Figure 3 is a schematic of the test model configuration. A soil box sized $1.8 \mathrm{~m}$ in length, $1.2 \mathrm{~m}$ in height, and $0.8 \mathrm{~m}$ in width was used. A different arrangement of soil-cement columns was implemented in each model, giving a treatment area ratio $\left(A_{r}\right)$ of about $30 \%$. It was assumed that the end of the columns reached the surface of the non-liquefiable soil layer.

After the construction of the DSM columns, an 18-kg rigid box with dimensions of $40 \times 40 \mathrm{~cm}$ was placed on the DSM columns as a model raft foundation of a three-story building. Several PWP transducers and accelerometers were installed in the soil model (Figure 3). The vertical displacement of the soil surface was measured by four Linear Variable Differential Transformer (LVDT) sensors. The models were shaken by sinusoidal waves at a 350-gal input level at a frequency of $3 \mathrm{~Hz}$ for a duration of $5 \mathrm{~s}$.

Table 2 summarizes the experiments in which the effects of column type were investigated. As shown earlier, the first model was unimproved and each of the second, third, and fourth models contained several DSM columns. The improvement area ratio was $30 \%$ in these three models. Figure 4 shows different patterns and placement of the DSM columns. In each model, the foundation is located on top of the DSM columns.
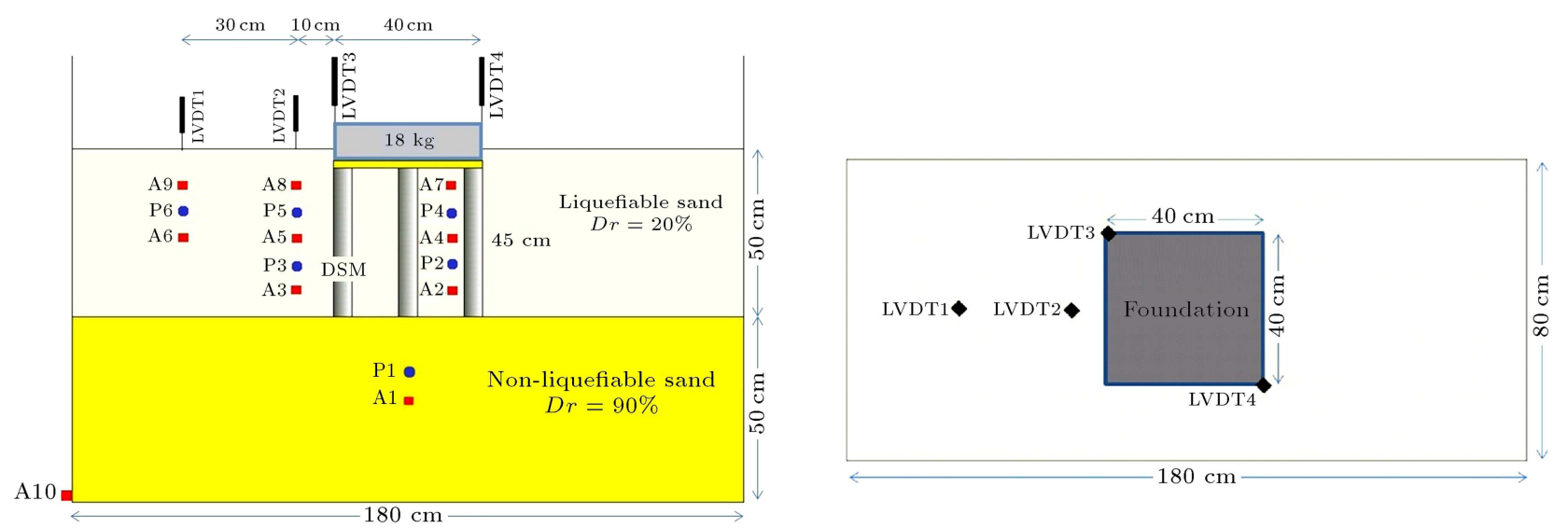

Figure 3. Configuration of $1 \mathrm{~g}$ model tests. 
Table 2. Test arrangements.

\begin{tabular}{ccccc}
\hline Test ID & $\boldsymbol{A}_{\boldsymbol{r}}(\boldsymbol{\%})$ & Pattern & Acc. (g) & $\begin{array}{c}\text { Improvement } \\
\text { length } \mathbf{( c m )}\end{array}$ \\
\hline UNI & 0 & Unimproved & 0.35 & 0 \\
SQP & 30 & Square & 0.35 & 45 \\
TRP & 30 & Triangular & 0.35 & 45 \\
SGP & 30 & Single & 0.35 & 45 \\
\hline
\end{tabular}

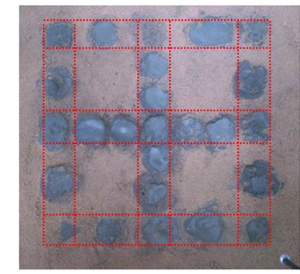

(a)

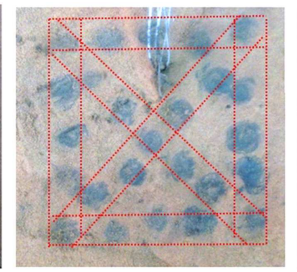

(b)

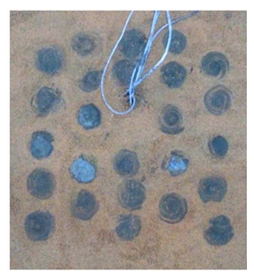

(c)
Figure 4. Deep Soil Mixing (DSM) column patterns: (a) square (SQP), (b) triangular (TRP), and (c) single (SGP).

\section{Experimental result and discussion}

\subsection{Settlement}

Two LVDTs were used to measure the settlement of the foundation. Figure 5 shows the amount of settlement caused by shaking at $0.35 \mathrm{~g}$. Figure 6 shows photographs of the UNI test model before and after shaking in which liquefaction-induced deformation can be clearly seen. The settlement measurements indicate that the DSM columns reduced vertical settlement of the foundation and the nearby unimproved area in comparison to the results of the UNI test. Figure 5 shows that from $T=2 \mathrm{sec}$ to $T=4 \mathrm{sec}$, since the beginning of the tests, there was a large difference between foundation settlements of UNI test sample and in other tests. The initial rapid settlement shows very fast softening of the subsoil. The generation of maximum Excess Pore Water Pressure (EPWP) in the

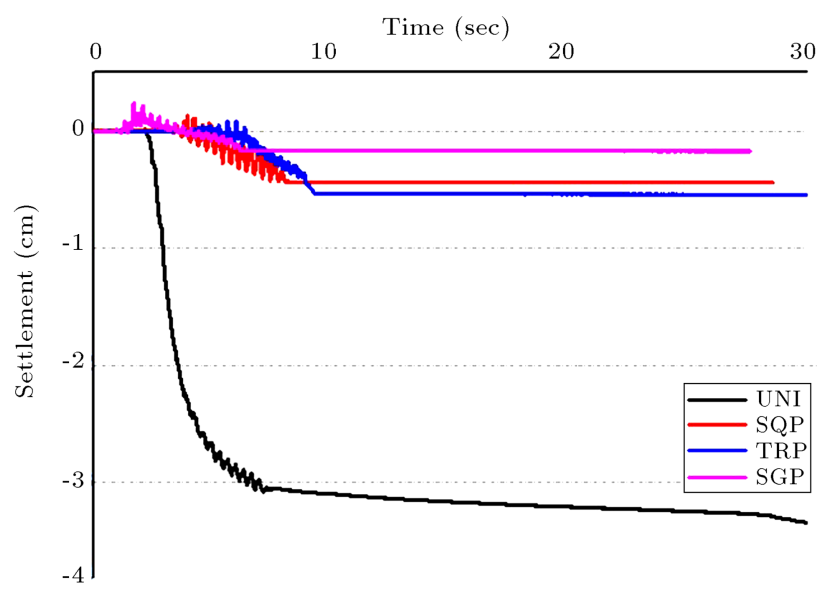

Figure 5. Settlement of foundation after $0.35 \mathrm{~g}$ of shaking. early cycles is also in accordance with the expected behavior.

Settlement in SQP (square), TRP (triangular), and SGP (single) tests appears to be reasonably controlled. DSM improvement decreased the rate and maximum amount of settlement and delayed the settlement initiation time. Changes in the column implementation pattern had little impact on foundation settlement and the free field surface. The settlement of the foundation in the improved soil cases was about $10 \%$ that of unimproved soil; however, the SGP test showed the best results for settlement reduction.

One main feature of the DSM columns is their ability to support overlying structures even if liquefaction occurs in the surrounding soil, which reduces settlement. In the presented models, the DSM columns were extended to the top of the stiff soil layer (nonliquefiable dense layer), but did not penetrate it. No crack or fracture was found on the DSM columns and suitable performance was observed in the tests. The columns in the SQP, TRP, and SGP tests remained undamaged, even after shaking (Figure 2).

Figure 5 shows that all foundation settlements occurred within the shaking duration of $5 \mathrm{~s}$ in the SQP, TRP, and SGP tests. In the UNI test, however, $90 \%$ of foundation settlements occurred during shaking, with a small portion contributed by post-shaking soil reconsolidation due to excess PWP dissipation. This means that the inertial forces caused by shaking played an important role in reshaping the soil foundation system $[20,21]$. In addition, a large portion of foundation settlement occurred because of the penetration of the footing into the liquefied soil [21].

\subsection{Excess PWP}

PWP transducers were installed at different locations in the soil to record the time history of the excess PWP. PWP records from depths of 4.5 and $7.5 \mathrm{~m}$ showed that high excess PWP developed in the early stages of shaking and was maintained during shaking. Figure 7 shows that excess pore pressure under the foundation developed during the three cycles of shear deformation in unimproved soil (UNI test; $z=-7.5$ $\mathrm{m})$. It appears that the development of excess pore pressure is initiated by a minimum shear strain of almost $1 \%$. In this study, the time histories of the 


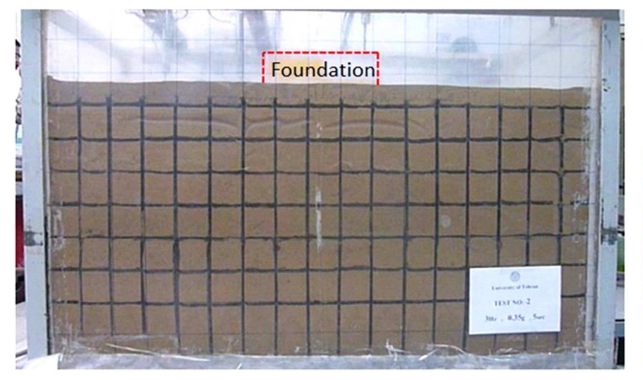

(a)

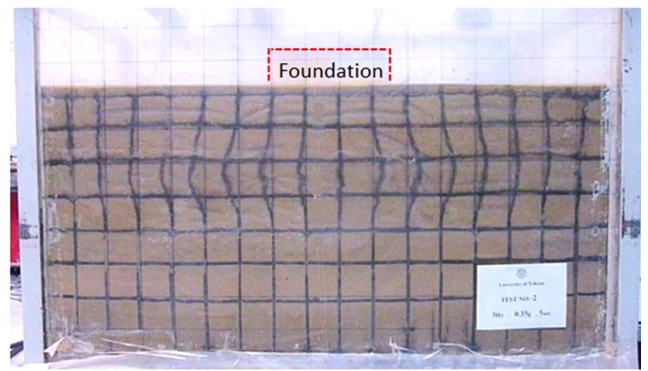

(b)

Figure 6. Model deformation showing liquefied layer: (a) Before shaking, and (b) after shaking.

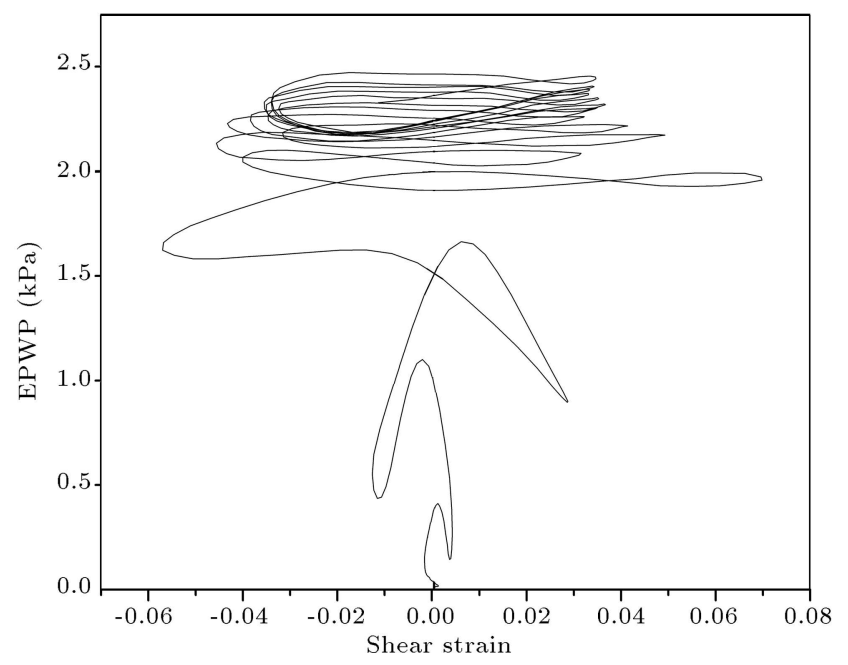

Figure 7. Excess pore water pressure vs. shear strain in UNI test $(z=-7.5)$.

normalized excess PWP $(\mathrm{Ru})$ were recorded at different locations.

In Figure 8, at deeper locations, the excess PWP started to dissipate after shaking and increase in the shallower layers because of the upward movement of water from the lower layers. Such a trend was observed during the 1995 Kobe earthquake, where upward seepage was evident for up to an hour after the earthquake [21]. This water flow could reduce the strength of the shallower layer or generate secondary liquefaction, causing large settlement or loss of bearing capacity [22]. Figure 8 shows that the excess PWP in the DSMimproved zone was less than that in the unimproved zone (free field) at different depths. A comparison of the improved and unimproved tests clearly shows that Ru decreased after DSM column improvement. This difference was more evident at a greater depth $(-7.5 \mathrm{~m})$. A decrease in excess PWP was $20 \%$ to $50 \%$ depending on the depth.

Figure 8 shows no significant difference in the increase rate of pore water pressure in the three column patterns; however, single and triangular patterns showed a slightly less increase in pore pressure than the foursquare pattern, especially at greater depths. This figure also shows negative PWP, or suction, in the soil enclosed by the columns in the first cycles of shaking. This could result from a reduction in water level and permeability, which led to the deterioration of the water flow between the DSM columns. Suction was

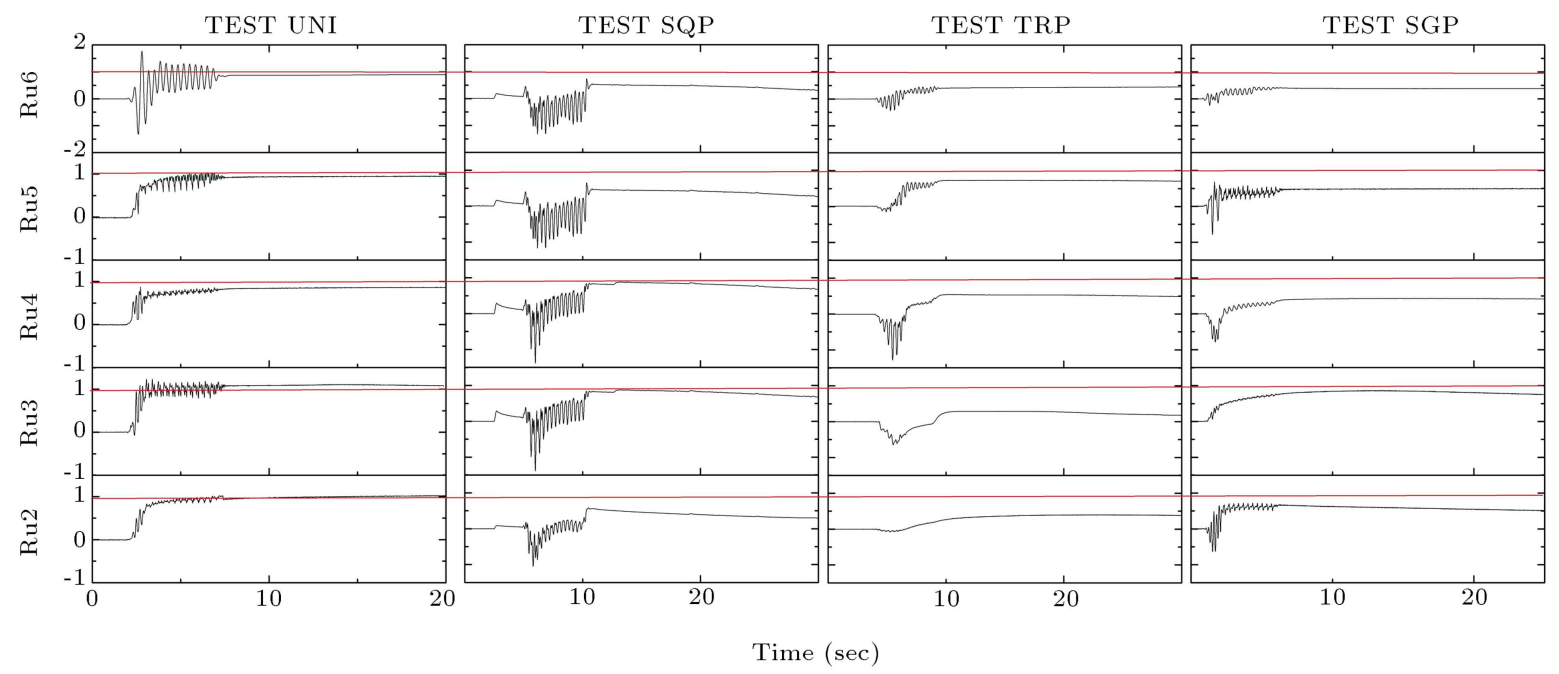

Figure 8. Time histories of normalized excess Pure Water Pressure (PWP) (Ru) at different locations. 
also seen in areas close to the walls of the box. This is the limitation of the rigid box physical model, and this error can be controlled using a laminar box [21].

In the UNI test, the $\mathrm{Ru}$ values below the foundation were lower than the free field values at the same levels. This could be completely reverse if there was no foundation placed on the soil, because the soil near the surface is more sensitive to liquefaction than the soil at greater depths [21]. Earlier centrifuge and $1 \mathrm{~g}$ shaking table tests on foundations supported by liquefiable sand have revealed that excess PWP is lower under the foundation than that in the free field [23,24]. This can be explained by the shear-induced dilative soil response during the deformation of the saturated soil below the footing. Moreover, foundation loads attenuate the liquefaction potential [25]. A similar behavior was observed in $1 \mathrm{~g}$ shaking table tests by Koga and Matsuo (1990) [26] and Sadrekarimi and Ghalandarzadeh (2005) [20].

\subsection{Soil behavior}

Figure 9 shows the acceleration time histories for the SQP test at $0.35 \mathrm{~g}, 3 \mathrm{~Hz}$, and $5 \mathrm{~s}$ of shaking. During shaking, the acceleration amplitude in the soil decreased from the bottom of the soil to the surface in response to the increase in PWP and the consequent liquefaction. The dynamic shear stress and shear strain time series were computed at different depths for each model using accelerometer array data. In these

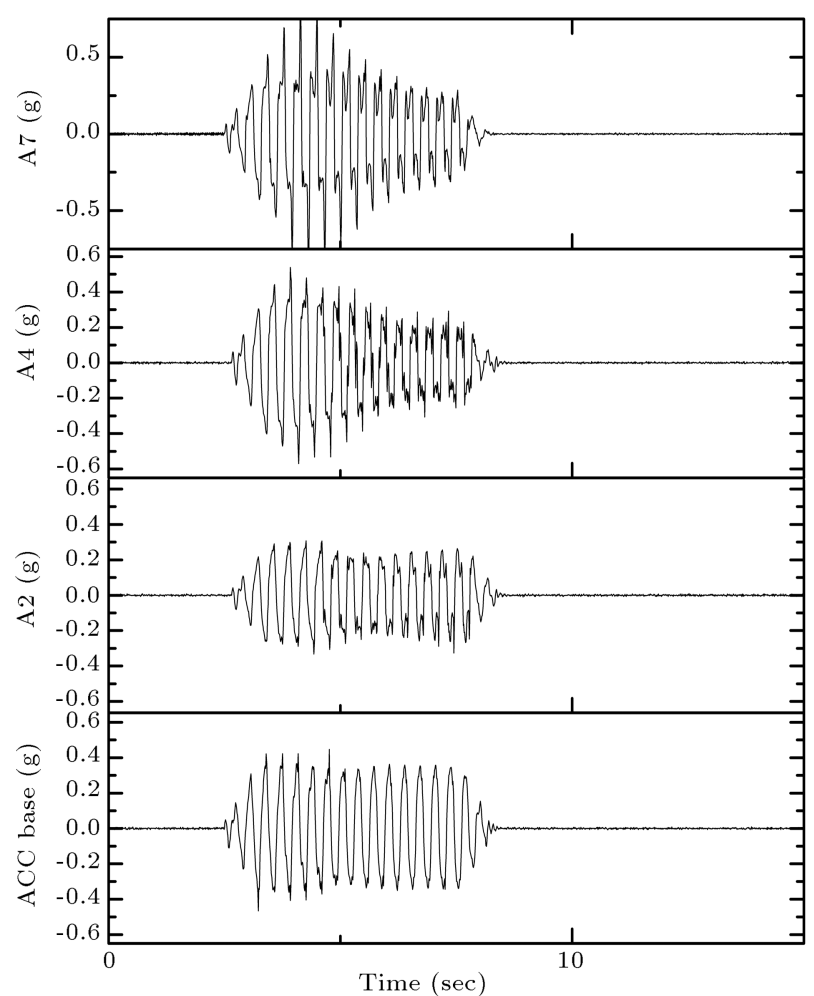

Figure 9. Acceleration time history models for SQP at $0.35 \mathrm{~g}, 3 \mathrm{~Hz}$, and $5 \mathrm{~s}$ of shaking. analyses, a 1D shear beam condition was assumed, and the procedures developed by Brandenberg et al. (2009) [27] and Kamai and Boulanger (2010) [28] were used.

The shear strain was computed through double integration of acceleration to obtain the horizontal displacement and, then, to differentiate the displacement with respect to depth to produce the shear strain. A high-pass Butterworth filter was applied to accelerations characterized by an order of 4 and a corner frequency (fc) of $1.0 \mathrm{~Hz}$, which gives reasonable displacement. In improved models, the stress-strain responses cannot be used to identify how the shear stresses are distributed between columns and the surrounding soil, but can provide a basis for evaluating how the columns affect the overall system stiffness [18]. By calculating the cyclic shear strain and shear stress, the stress-strain behavior of the soil can be plotted. Figure 10 shows the stress paths at depths of -4.5 and $-7.5 \mathrm{~m}$ in the UNI test. The stress paths indicated that the effective stress in the soil decreased significantly as excess pore pressure developed in the unimproved soil.

The stress-strain behavior of the unimproved soil is shown in Figure 11. In the UNI test, soil stiffness in the free field decreased rapidly and the stress-strain curve became a horizontal line denoting very high damping and zero stiffness. The unimproved soil under the foundation showed stiffer behavior than the free field stress points.

The stress-strain behavior of the improved soil models is shown in Figure 12. In the models of SQP, TRP, and SGP tests, it was predicted that soil would maintain its resistance. The maximum shear strain in the soil was lower for the improved cases $(2 \%-5 \%)$ than that for the unimproved case $(\sim 8 \%)$. In the shallow layers of the improved models, the peak shear strain was observed in the stress-strain responses at $25 \%-60 \%$ of the values shown in the UNI test, despite the similarity of the peak shear stresses. These results indicate that the overall behavior of the DSM columns increased their ability to stiffen the soil profile. According to Figure 13, the shear modulus of the soil increased by $70 \%$, especially at the first eight cycles after implementation of the stiff DSM columns; thus, the columns helped reduce the shear strain in the surrounding soil and lateral displacement in the soil. Figure 12 shows the stress-strain hysteresis loops for SGP, TRP, and SQP patterns at two depths under the foundation. A comparison of the results of different patterns shows that the single pattern exhibits roughly stiffer shear behavior and less strain under the same shear stress than the other patterns. It can be said that, in this pattern, the volume of soil, which was enclosed between the columns, was lower than that for the other two patterns; therefore, the shear deformation decreased. Moreover, it can be seen that 


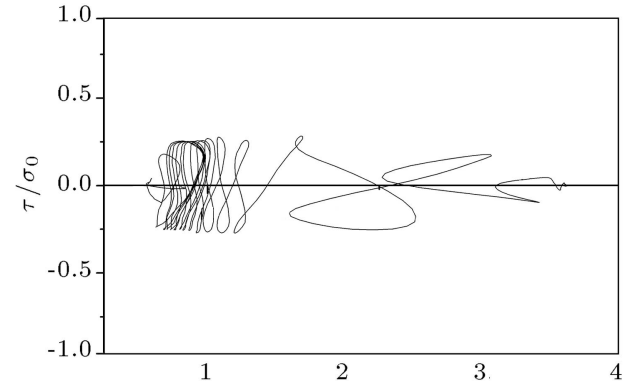

(a)

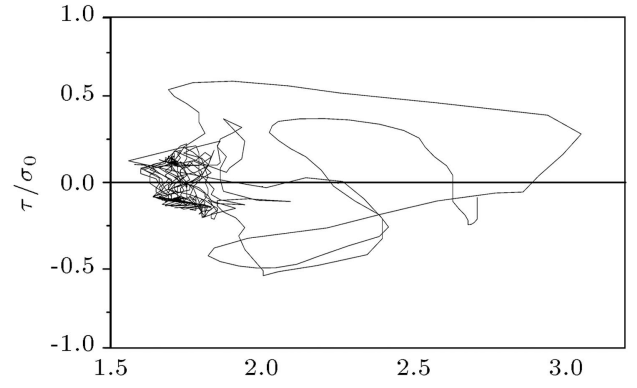

(b)

Figure 10. Shear stress vs. shear strain of unimproved soil test: (a) $Z=-7.5 \mathrm{~m}$ and (b) $Z=-4.5 \mathrm{~m}$.

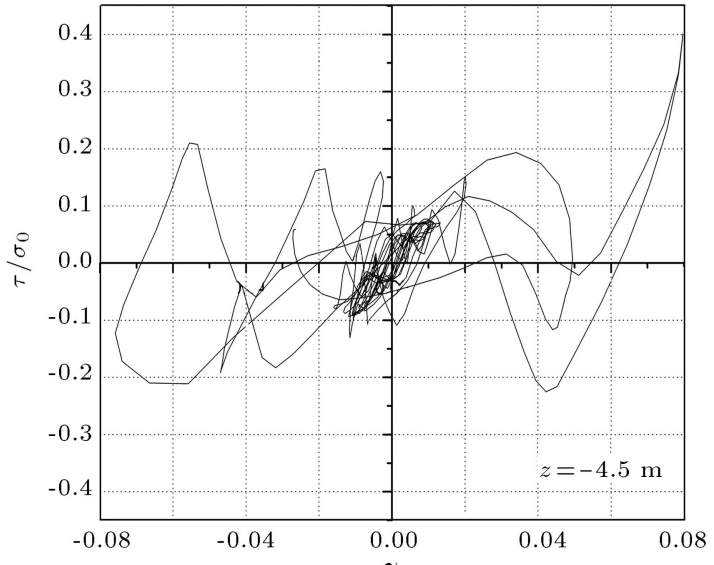

(a)

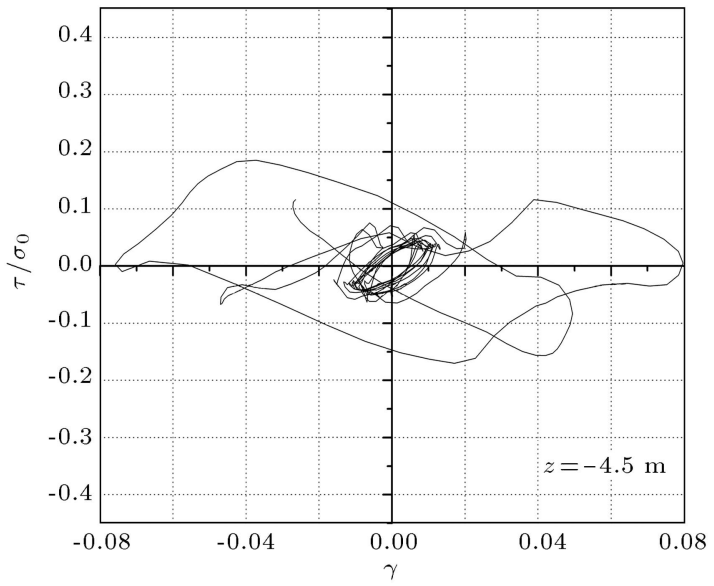

(c)

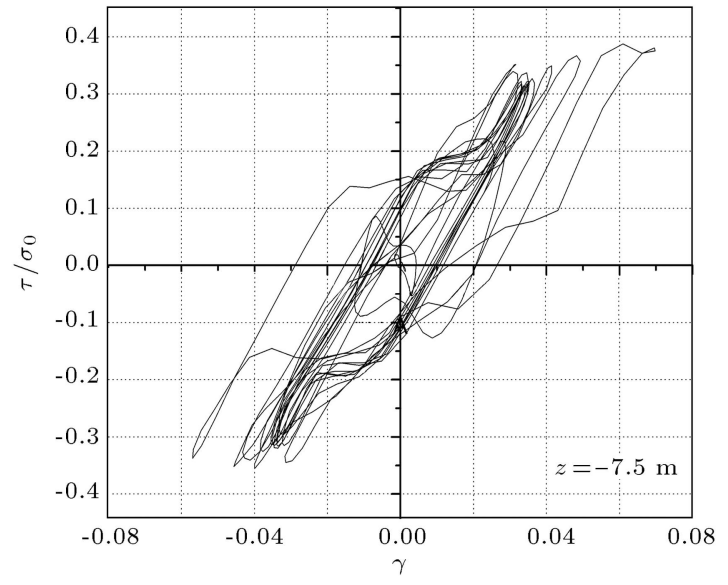

(b)

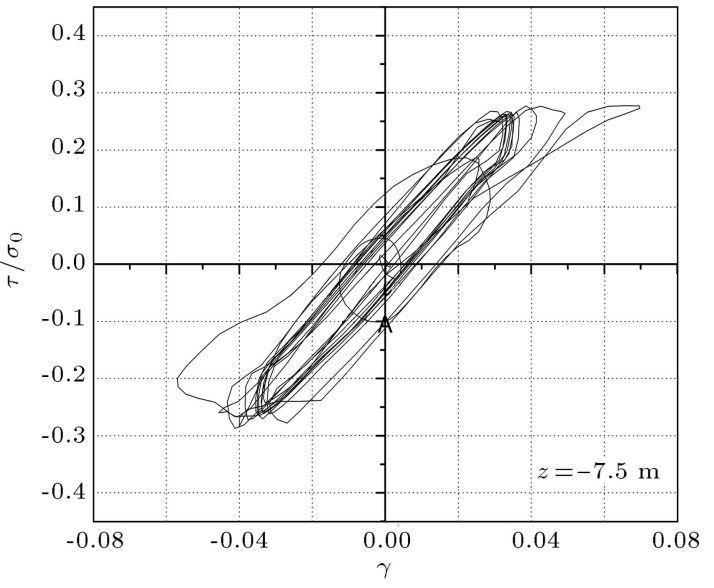

(d)

Figure 11. Stress paths of unimproved soil under foundation (UNI test): (a) and (b) under foundation, and (c) and (d) outside of foundation.

the shear strain at the first loading cycle in the free field was certainly greater than that in the improved areas in all tests. The DSM columns under the foundation slightly affected the shear behavior of the nearby area and the areas farther away from the foundation.

\subsection{Analysis of shear reinforcing effect of DSM columns}

Estimates of the increase of soil shear strength induced by the DSM columns were analyzed using the relation provided by Baez (1995) [14] and were extended to soil-cement columns method by Durğunoglu (2006) [15], which assumes shear strain compatibility between columns and the surrounding soil. It was then analyzed using the theoretical bounds proposed by Gueguin et al. (2013) [16] and the design equation presented by Rayamajhi et al. (2014) [13], which consider differences in the shear strain between the columns and surrounding soil. According to Rayamajhi et al. (2013) [13], the average shear modulus for improved 


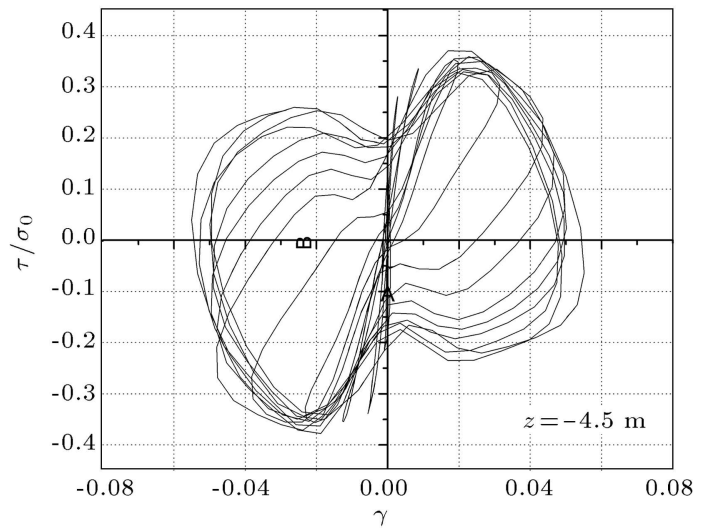

(a)

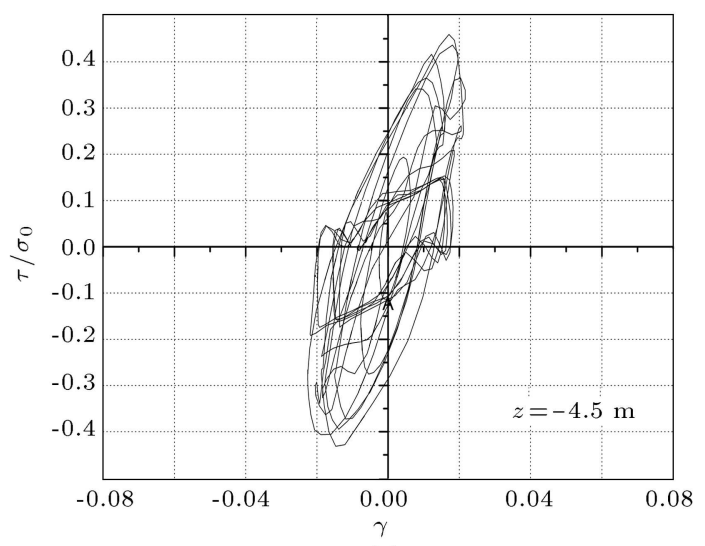

(c)

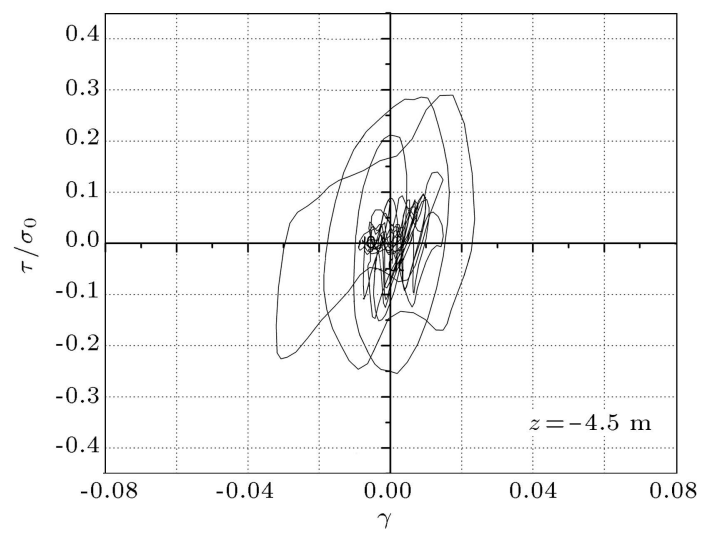

(e)

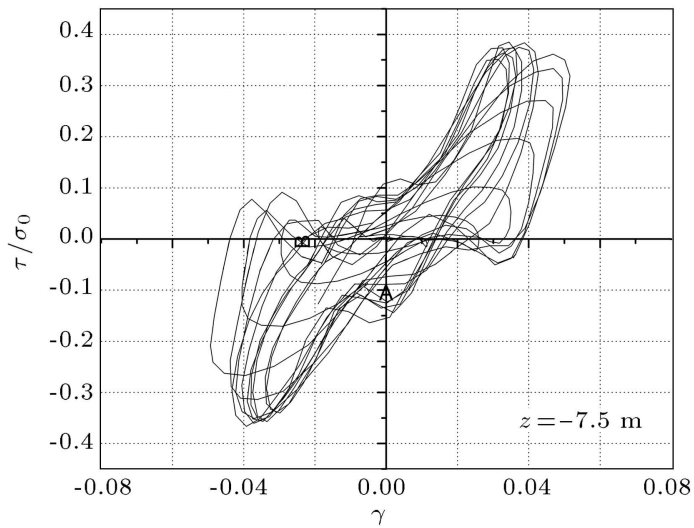

(b)

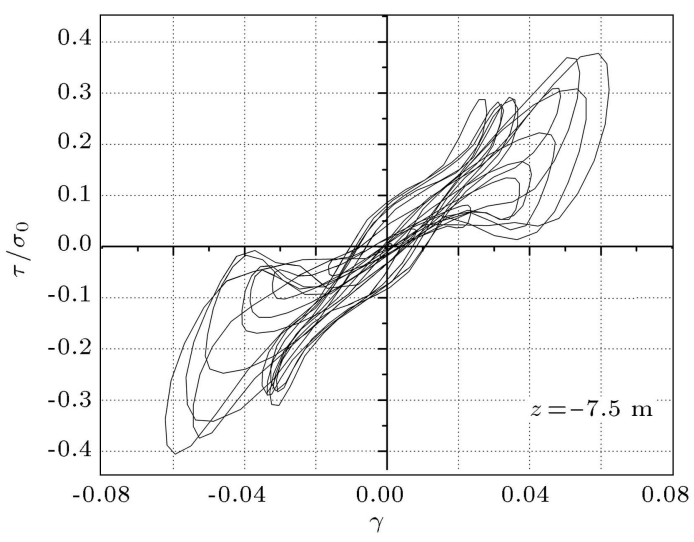

(d)

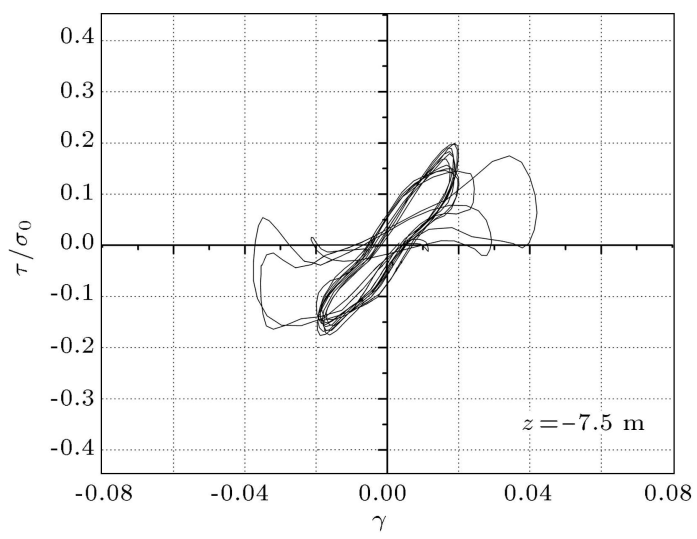

(f)

Figure 12. Shear stress vs. shear strain in improved soil under the foundation: (a) and (b) SQP; (c) and (d) TRP; and (e) and (f) SGP.

soil, $G_{a v g}$, is divided by the small-strain shear modulus for unimproved soil, $G_{s}$, and can be estimated as follows:

$$
\begin{aligned}
& \frac{G_{a v g}}{G_{s}}=\left(\frac{\tau_{a v g}}{\gamma_{a v g}}\right) \cdot \frac{1}{G_{s}}=\frac{1+A_{r} \cdot\left(\gamma_{r} \cdot G_{r}-1\right)}{1+A_{r}\left(\gamma_{r}-1\right)}, \\
& \gamma_{r}=\frac{\gamma_{\text {soil-cement }}}{\gamma_{\text {soil }}}=1.04 .\left(G_{r}\right)^{-0.65}-0.04,
\end{aligned}
$$

where $\tau_{a v g}$ is the average shear stress for the improved soil, $\gamma_{a v g}$ is the average shear strain for improved soil, $G_{r}=G_{c} / G_{s}$ is the shear modulus ratio, $G_{c}$ is the small-strain shear modulus of the column, $\gamma_{r}$ is the shear strain ratio, $\gamma_{\text {soil-cement }}$ is the shear strain in the soil-cement column, $A_{r}$ is the treatment area ratio by DSM, and $\gamma_{\text {soil }}$ is the shear strain in the soil. This relationship considers shear strain incompatibility between the columns and the surrounding soil using the term $\gamma_{r}$. When $\gamma_{r}=1$, this relation corresponds to the assumption of shear strain compatibility [5]. 


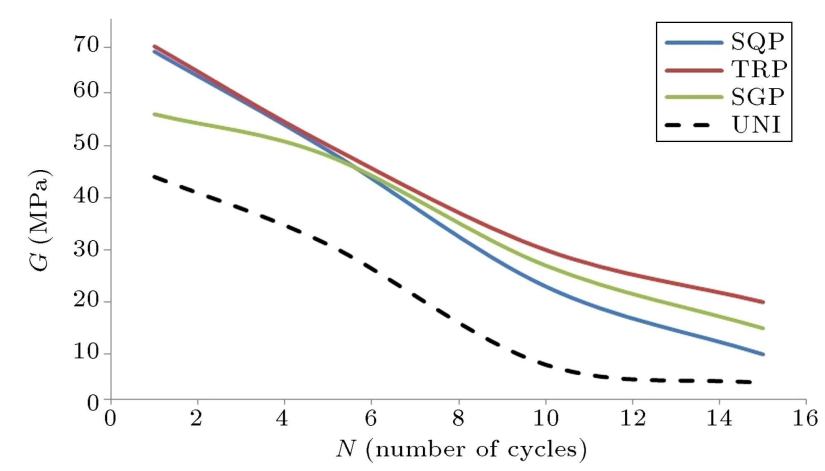

Figure 13. Plot of shear modulus $(G)$ vs. number of cycles $(N)$ for three Deep Soil Mixing (DSM) patterns and the unimproved case.

In this research, the shear stiffness values for the unimproved soil profile $\left(G_{s}\right)$ and experimental shear stiffness values for improvement tests $\left(G_{a v g}\right)$ were calculated for cycles of each hysteresis curve in the UNI test (Figure 11) and, also, for cycles on the hysteresis chart related to SQP, TRP, and SGP tests for points in soil and under the foundation (Figure 12). Figure 13 shows that an increase in the number of cycles during shaking and in PWP gradually decreased the shear stiffness. Soil improvement using DSM columns also increased the shear stiffness in comparison to that of the unimproved soil.

The small-strain shear moduli for the DSM columns $\left(G_{c}\right)$ were estimated to be $110 \mathrm{MPa}$. Young's secant modulus was evaluated by unconfined compression testing on the DSM column material after three days of curing (immediately after the shaking table tests). This secant shear modulus can be calculated using the theory of elasticity at a Poisson's ratio of 0.2. The small-strain shear modulus for the DSM column was then estimated to be $50 \%$ greater than the secant value. This is the result of known limitations of conventional unconfined compression testing for determining small-strain moduli [14].

In Figure 14, the normalized average shear modulus ratio $\left(G_{\text {avg }} / G_{s}\right)$ computed using Eq. (1) and experimental $G_{\text {avg }} / G_{s}$ related to SQP, TRP, and SGP tests were plotted versus the number of cycles for the $A_{r}=30 \%$. Figure 14 shows that changing the DSM column pattern had little impact on the increase of shear stiffness during shaking; however, the SQP pattern had less shear stiffness than other patterns. The experimental $G_{a v g} / G_{s}$ values for improvement cases were close to $G_{a v g} / G_{s}$ using Eq. (1) in the shakes before the fifth cycle; however, with increasing cycles, there was a significant difference between the two values of $G_{a v g} / G_{s}$.

\section{Conclusion}

In this experimental study, four shaking table tests

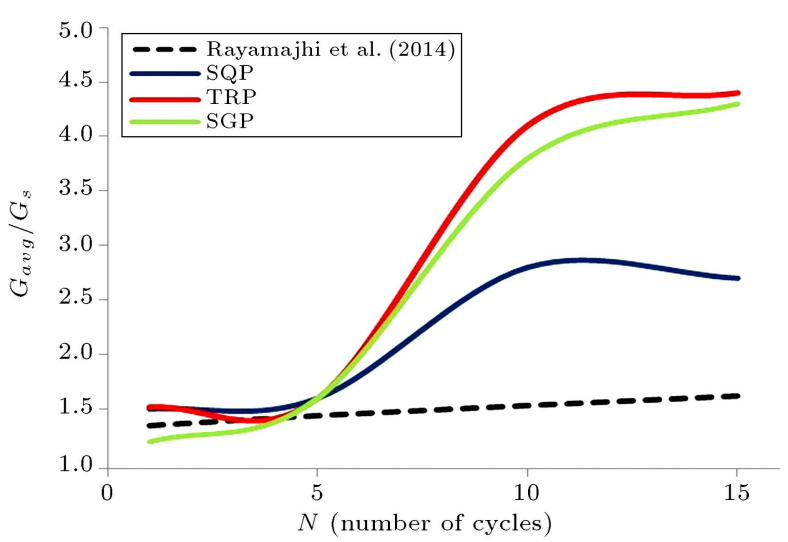

Figure 14. Plot of average shear modulus for Deep Soil Mixing (DSM) columns based on the shear reinforcement mechanism from shaking table tests using Rayamajhi et al. [13].

were conducted to investigate the effect of DSM columns and the patterns of column implementation on liquefiable sand. An unimproved soil model and three improved soil models using DSM columns in different patterns were tested. The major observations of testing are given below:

(a) DSM improvement can reduce the rate of settlement and the maximum amount of settlement. The settlement of a foundation in the improved soil cases was $10 \%$ that of the unimproved case. The implementation pattern of the columns had little impact on settlement of the foundation or the free field surface; however, the single pattern showed lower settlement than the other patterns;

(b) Comparison of the unimproved soil case and the improved cases clearly showed that Ru decreased after DSM column improvement. This decrease in excess pore water pressure was $20 \%$ to $50 \%$ depending upon the depth. The single and triangular patterns showed lower excess pore pressure than the foursquare pattern, especially at greater depths;

(c) In the unimproved soil case, the $\mathrm{Ru}$ value during shaking was lower below the foundation than that in the free field at the same depth. The foundation loads decreased the liquefaction potential as has previously been proven by Adalier et al. (1998) [24], Koga and Matso (1990) [26], and Sadrekarimi and Ghalandarzadeh (2005) [20];

(d) Negative pore water pressure (or suction) was recorded between the Deep Soil Mixing (DSM) columns in the initial cycles of shaking;

(e) During shaking, the maximum shear strain $\left(\gamma_{\max }\right)$ in the improved soil was lower $(2 \%-5 \%)$ than that in the unimproved soil $(\sim 8 \%)$. In the shallow layers of the improved models, the peak shear 
strain observed in the stress-strain responses was $25 \%-60 \%$ of the values shown in the UNI test, despite the similar rates of increase in peak shear stress;

(f) The increase in shear stiffness from the DSM columns by $A_{r}=30 \%$ was roughly 1.5 times for the first five cycles and 3 times for the subsequent cycles in comparison to that of the unimproved soil. The column implementation pattern had little impact on the increase of shear stiffness during shaking; however, the SQP pattern had lower shear stiffness than other patterns;

(g) The results of the current shaking table tests and the analysis by Rayamajhi et al. (2013) [13], which considers flexure of the reinforcing columns, provided reasonable (slightly low) estimates for the effect of shear reinforcement of DSM columns in the low shear strain and the first cycles;

(h) The results of this study showed that the single (SGP) and foursquare (SQP) patterns could transfer acceleration more easily and impose greater acceleration on the overhead structure;

(i) In order to decrease the hazard of liquefaction, it appears that the single pattern is a more appropriate alternative than the other two alternatives. The major reason for this is that the pore water pressure and foundation settlement for the single pattern were lower than those for the foursquare and triangular patterns.

\section{References}

1. Seed, H.B. and Idriss, I.M "Analysis of soil liquefaction: Niigata earthquake", Journal of the Soil Mechanics and Foundations Division, 93(3), pp. 83108 (1967)

2. Youd, T.L. "Liquefaction-induced damage to bridges", Report U.S Transportation Research Record, 1411, pp. 35-41 (1993).

3. Elgamal, A.W., Zeghal, M., and Parra, E. "Liquefaction of reclaimed island in Kobe, Japan", Journal of Geotechnical Engineering, 122(1), pp. 39-49 (1996).

4. National Research Council (US). Committee on Earthquake Engineering. "Liquefaction of soils during earthquakes", 1, pp. 4-6 (1985).

5. Nguyen, T.V., Rayamajhi, D., Boulanger, R.W., Ashford, S.A., Lu, J., Elgamal, A., and Shao, L. "Design of DSM grids for liquefaction remediation", J. Geotech. Geoenviron. Eng., 139(11) pp. 1923-1933 (2013).

6. Namikawa, T., Koseki, J., and Suzuki, Y. "Finite element analysis of lattice-shaped ground improvement by cement mixing for liquefaction mitigation", Soils and Found, 47(3), pp. 559-576 (2007).
7. Derakhshani, A., Takahashi, N., Bahmanpour, A. Yamada, S., and Towhata, I. "Experimental study on effects of underground columnar improvement on seismic behavior of quay wall subjected to liquefaction", Proc. of 2011Pan-Am CGS Geotechnical Conference, Toronto, Canada (2011).

8. O'Rourke, T.D. and Goh, S.H. "Reduction of liquefaction hazards by deep soil mixing", NCEER/INCEDE Workshop, MCEER, Univ. at Buffalo, State Univ. of New York, Buffalo, NY (1997).

9. Elgamal, A., Lu, J., and Forcellini, D. "Mitigation of liquefaction-induced lateral deformation in a sloping stratum: Three-dimensional numerical simulation", $J$. Geotech. Geoenvir. Eng., ASCE, 135(11), pp. 16721682 (2009).

10. Asgari, A., Oliaei, M., and Bagheri, M. "Numerical simulation of improvement of a liquefiable soil layer using stone column and pile-pinning techniques", Soil Dyn. Earthquake. Eng., 51, pp. 77- 96 (2013).

11. Green, R.A., Olgun, C.G, and Wissmann, K.J. "Shear stress redistribution as a mechanism to mitigate the risk of liquefaction", In Geotechnical Earthquake Engineering and Soil Dynamics IV, pp. 1-10 (2008).

12. Olgun, C.G. and Martin, J.R. "Numerical modeling of the seismic response of Columnar reinforced ground", In Geotechnical Earthquake Engineering and Soil Dynamics IV, pp. 1-11 (2008).

13. Rayamajhi, D., Nguyen, T.V., Ashford, S.A., Boulanger, R.W., Lu, J., Elgamal, A., and Shao, L. "Numerical study of shear stress distribution for discrete columns in liquefiable soils", J. Geotech. Geoenviron. Eng, 140(3), 04013034-1 (2013).

14. Baez, J.I. "A design model for the reduction of soil liquefaction by vibro-stone columns", PhD Thesis, Univ. of Southern California, Los Angeles, CA (1995).

15. Durgunoğlu, H.T. "Utilization of high modulus columns in foundation engineering under seismic loadings", US 8th National Conference on Earthquake Engineering, San Francisco, CA., USA (2006).

16. Gueguin, M., Buhan, P., and Hassen G. "A homogenization approach for evaluating the longitudinal shear stiffness of reinforced soils: column versus cross trench configuration", Int. J. Numer. Anal. Meth. Geomech, 37, pp. 3150-3172 (2013).

17. Rayamajhi, D., Nguyen, T.V., Ashford, S.A., Boulanger, R.W., Lu, J., Elgamal, A., and Shao, L. "Numerical study of shear stress distribution for discrete columns in liquefiable soils", J. Geotech. Geoenviron. Eng., 140(3), 04013034-1 (2013).

18. Rayamajhi, D. "Shear reinforcement effects of discrete columns in liquefiable soils displacements", PhD Thesis, Oregon: Oregon State University (2014).

19. Iai, S. and Sugano, T. "Soil-structure interaction studies through shaking-table tests", Proceedings of $2 n d$ International Conference on Earthquake Geotechnical Engineering, Lisbon, pp. 927-940 (1999). 
20. Sadrekarimi, A. and Ghalandarzadeh, A. "Evaluation of gravel drains and compacted sand piles in mitigating liquefaction", Proceedings of the ICE-Ground Improvement, 9(3) pp. 91-104 (2005).

21. Shibata, T., Oka, F., and Ozawa, Y. "Characteristics of ground deformation due to liquefaction", Soils and Foundations, 36, pp. 65-79 (1996).

22. Yoshimi, Y. and Kuwabara, F. "Effects of subsurface liquefaction on the strength of surface soil", Soils and Foundations, 13(2), pp. 67-81 (1973).

23. Whitman, R.V. and Lambe, P.C. "Earthquake like shaking of a structure founded on saturated sand", Proceedings of the International Conference on Geotechnical Centrifuge Modelling, Paris, pp. 529-538 (1998).

24. Adalier, K., Elgamal, A.W., and Martin, G.R. "Foundation liquefaction countermeasures for earth embankments", Journal of Geotechnical and Geoenvironmental Engineering, ASCE, 124(6), pp. 500-517 (1998).

25. Adalier, K., Elgamal, A.W., Meneses, J., and Baez, J.I. "Stone columns as liquefaction countermeasure in non-plastic silty soils", Soil Dynamics and Earthquake Engineering, 23(7), pp. 571-584 (2003).

26. Koga, Y. and Matsuo, O. "Shaking table tests of embankments resting on liquefiable sandy ground", Soils and Foundations Journal, 30(4), pp. 162-174 (1990).

27. Brandenberg, S.J., Wilson, D.W., and Rashid, M.M. "Weighted residual numerical differentiation algorithm applied to experimental bending moment data", J. of Geotech. and Geoenviron. Eng., 136(6), pp. 854-863 (2009).

28. Kamai, R. and Boulanger, R.W. "Characterizing localization processes during liquefaction using inverse analyses of instrumentation arrays", Meso-Scale Shear Physics in Earthquake and Landslide Mechanics, I. Vardoulakis, pp. 219-238 (2010).

\section{Biographies}

Hesam Dehghan Khalili received his BSc degree in Civil Engineering from Hormozgan University of Technology in 2006 and his MSc degree in Geotechnical Engineering from Shahid Beheshti University in 2008. He has professional experience in design and execution of soil improvement methods. He is currently a $\mathrm{PhD}$ student at the School of Civil Engineering at the University of Tehran. His research and engineering interests include experimental soil mechanics, liquefaction problems, soil improvement, physical modeling, and designing DSM and jet grouting to solve foundation settlement problems.

Abbas Ghalandarzadeh is an Associate Professor at School of Civil Engineering, University of Tehran, where he is also currently the Head of the Soil Mechanics and Centrifuge Laboratory. He received his $\mathrm{PhD}$ in Geotechnical Engineering from the University of Tokyo in 1997. He is a member of the Technical Committee of $\mathrm{TC} 2$ of the International Society of Soil Mechanics and Geotechnical Engineering. His research interests are mainly in the area of experimental geotechnics, particularly in model and element testing. Dr. Ghalandarzadeh has undertaken much research in the area of Earthquake Geotechnical Engineering including specifically the dynamic behavior of rockfill dams with asphalt concrete cores, the seismic behavior of quay walls, reinforced earth and soil improvement techniques, and more recently dynamic behavior of all types of geomaterials.

Majid Moradi is an Associate Professor at School of Civil Engineering, College of Engineering, University of Tehran, Iran. He received his BSc in Civil Engineering in 1989 and MSc in Geotechnical Engineering in 1992 both form University of Tehran and obtained $\mathrm{PhD}$ in Geotechnical Engineering from University of Manchester, UK in 1999. He has broad experience in physical modeling in geotechnics, especially employing geotechnical centrifuge facility. Moreover, he has supervised numerous MSc and $\mathrm{PhD}$ students with the research subject of the physical and numerical modeling. He is the author and co-author of several research papers in the field of geotechnical engineering, especially physical modeling with centrifuge facility.

Reza Karimzadeh received his BSc degree in Civil Engineering from Tabriz University in 2014 and his MSc degree in Geotechnical Engineering from University of Tehran in 2017. His present research interests include Shaking table and centrifuge physical modeling and geo-environmental problems. 